\section{DESIGN AND IMPLEMENTATION OF A NOVEL 6-DOF PLANAR}

MAGLEV POSETIONING SYSTEM

Y.C. Lai, J, Y, Yen

National Taiwan University, No.1, Sec. 4, Rooseveit Road, 106 Taipei, Taiwan

\section{Abstract}

This paper proposes a novel design of a single-deck and six degree-of-freedom (DOF) planar maglev positioning system. The proposed design does not depend on the conventional linear slideways, instead, the design consists of an array of fixed solenoid electromagnets and permanent magnet carrier stage. The basic idea is to come up with a solenoid excitation that can crcate a restoring force to position and to move the magnet carrier. This research uses the ANSOFT finite element analysis (FEA) software to analyze the effects of forces between solenoids and magnets, and builds a prototype model for experimental verification.

\section{6-DOF Planar Maglev System Design}

Due to the physical nature of the maglev system, the conventional designs are cither for very short range or long range with one moving DOF. Stacked design is necessary if higher DOF motion is desired. This article proposes a novel single-deck and 6-DOF planar maglev positioning system. Instead of the conventional double-deck design, the proposed system consists of an array of fixed electro-magnetic solenoid stators and a permanent magnet carrier stage. The system uses the excited solenoids to drive and to position the pennanent magnet carrier stage. The design is simpler in construction compared to the other single-deck planar maglev systems [1], [2], [3], and is able to extent to long range movements.

The goal of the analysis, based on the ANSOFT software, is to reach a configuration that can provide restoring forces to the carrier in all manners of carrier attitude deviation. The scales of the cylindrical solenoids in the system are $20 \mathrm{~mm}$ in the outside diameter, $10 \mathrm{~mm}$ in the inside diameter, $10 \mathrm{~mm}$ in height and 370 turns. The material for the permanent magnet is NafeB. Its diameter is $10 \mathrm{~mm}$, remanence is $1.29 \mathrm{~T}$ and coercivity is $990 \mathrm{kA} / \mathrm{m}$.

Figure 1 shows the 3D mimic framework of the magnets arrangement. Figure 2 and figure 3 show the $x$-direction and the $z$-direction force variations while keeping the magnet at different air gap altitudes. The repulsion $(F x)$ reaches maximum at $\pm 6 \mathrm{~mm}$. The buoyancy (Fz) rcaches its maximum at the center of the solenoid. Figure 3 shows that there maintains enough buoyancy force to elevate the carrier. Based on the analysis results, one can then derive workable excitation patterns with the solenoid array. From the analysis, a novel 6-DOF planar maglev positioning system is proposed as shown in figure 4 . The maglev platform has the 29 circular magnets with the 37 solenoids to form the array. Figure 5 shows the 5 horizontal magnets designed to provide buoyancy force and to control the carriet altitude. Figure 6 and 7 shows the situations when there are movernents in the $x$-direction and $y$-direction. Respectively, the 8 horizontal magnets will be controlled by the 12 solenoids to exert restoring force to the carrier. The corresponding forces that the magnet exerts are also shown in the figures. When yaw disturbance occurs as in figure 8 , the 4 bottom solenoids will be excited with different currents to provide restoring forces to the 4 horizontal magnets. Similar situation can be applied when there is roll disturbance as shown in figure 9 or pitch disturbance as shown in figure 10 . With this procedure, one will be able to control all 6-DOF of the maglev carrier stage. The force variations over different attitude disturbances are not shown here due to space limit. Figure $1 \mathrm{l}$ shows the prototype of the system with the 6 sensors.

\section{Conclusion}

By using proper combination of solenoids and horizontal magnets, it is possible to establish restoring forces to the carrier stage. This research derives workable excitation patterns with a solenoid array, demonstrates the working principle of a novel 6-DOF planar maglev positioning system and builds a prototype model for experimental verification.

References

[1] A. F. Flores Filho, A. A. Sușin, and M. A. da Silveira, "Application of Neodymium-iron-Boron permanent magnets on the assembling of a novel planar actuator," lEEE Tran. on Magnetics, Vol. 35, No. 5, pp.4034-4036, Sep. 1999.

[2] H. S. Cho, C. H. Im, and H. K. Jung, "Magnetic field analysis of 2-D permanent magnet array for planar motor," IEEE Tran, on Magnetics, Vol. 37, No. 5, pp.3762-3766, Sep. 2001.

[3] K. S. Jung and Y. S. Baek ' "Contact-Free Moving-Magnct Type of Micropositioner With Optimized Specification," IEEE Tran. on Magnetics, Vol. 38, No. 3, pp.1539-1548, May 2002.

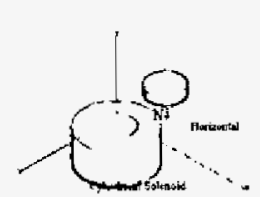

Fig. 1

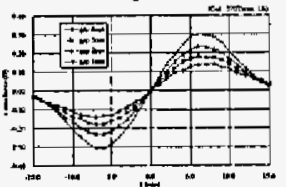

Fig. 2

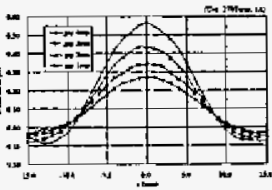

ing. 3
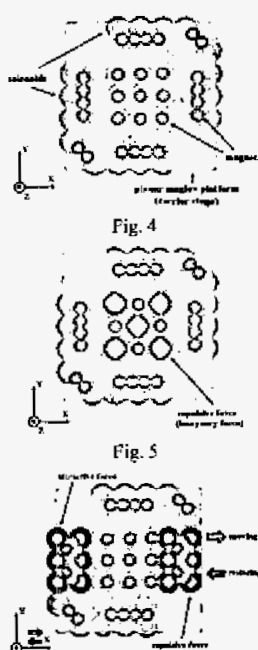

$\widetilde{0000}$

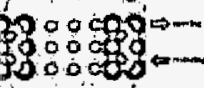

$8 ; 0$
Fig. 6

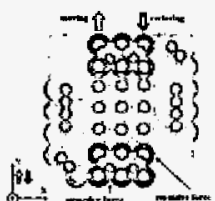

in 000

ig. 7
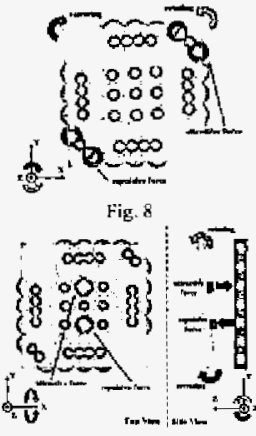

Fig. 9 